\title{
The Impacts of Psychological Distress on Life Satisfaction and Wellbeing of the Indian General Population During the First and Second Waves of COVID-19: A Comparative Study
}

\author{
Remya Lathabhavan ${ }^{1}$ (D) Shyamlin Sudevan ${ }^{2}$
}

Accepted: 8 December 2021

(C) The Author(s), under exclusive licence to Springer Science+Business Media, LLC, part of Springer Nature 2021

\begin{abstract}
The current study aims to understand the impact of psychological distress caused by the COVID-19 pandemic on life satisfaction and wellbeing, in the Indian context. The study also analyses the differences in these effects between the first and second waves of the pandemic. For this purpose, a survey was conducted during the two waves of the pandemic. Eight hundred eighty-four and 925 respondents participated in the first and second waves, respectively. The study showed that depression, anxiety, and stress negatively related to life satisfaction and wellbeing during both waves. The study also showed that the effects were stronger during the second wave compared to the first. Life satisfaction and wellbeing of women were found to be affected to a higher level than those of men, due to psychological distress. The study showed that a combined approach involving coping mechanisms and health care can help manage the psychological issues that arise with crisis situations such as the COVID-19 pandemic.
\end{abstract}

Keywords COVID-19 $\cdot$ Mental health $\cdot$ COVID-19 s wave $\cdot$ Comparative study $\cdot$ India

The COVID-19 pandemic has seriously affected the entire world and has raised health concerns among people (Kontoangelos et al., 2020; Lathabhavan \& Padhy, 2022). The health concerns are not only limited to high infection rates and death tolls, but also include mental health issues (Lathabhavan et al., 2021; Tandon, 2020). The mental health problems that have resulted from the pandemic and associated lockdowns have included depression, tension, insomnia, and suicidal tendencies (Hao et al., 2020; Wang et al. 2021a; Xiong et al., 2020). Such mental health concerns have been severe in middle-income Asian countries due to the economic challenges and limited medical resources available for the sustenance

Remya Lathabhavan

remya.1@vit.ac.in

Shyamlin Sudevan

sudevanshyamlin@gmail.com

1 Department of Technology Management, VIT University, Vellore, India

2 PayPal India, Bangalore, India 
of physical and mental well-being during these trying times (Lee et al., 2021; Wang et al. 2021d).

India is among the worst hit countries of COVID-19. The second wave of COVID-19 was severe in India and was associated with a plethora of complications and mental health concerns. As per the latest data, India reported 30,458,251 confirmed cases and 400,312 deaths (WHO, 2021). During the first wave of COVID-19, researchers and practitioners discovered the emergence of mental health concerns associated with the pandemic and resultant lockdown (Lathabhavan \& Vispute, 2021; Lathabhavan, 2021b). The second wave, which was characterized by high morbidity rates, shortages of oxygen and beds in hospitals, and complications such as emergence of new variants further exacerbated mental health problems among people (Lathabhavan, 2021c).

Depression has been a common mental health concern during the pandemic (Yom-Tov et al., 2021). COVID-19-related information from media sources, official websites, and discussions was one of the causes of depression among people (Ustun, 2021). Anxiety levels also increased over this period due to loved ones being infected, fear of becoming infected themselves, and often alarming pandemic news (E. P. H. Choi et al., 2020; Moghanibashimansourieh, 2020). The pandemic period also resulted in stress due to high infection rates and fear of contracting the disease (Lathabhavan, 2021a; Reznik et al., 2020). Such psychological distress factors have been found to negatively affect life satisfaction and wellbeing during the pandemic (El-Bardan \& Lathabhavan, 2021; S. X. Zhang et al., 2020).

Psychological distress adversely affects life satisfaction and wellbeing during normal times as well. Earlier studies have shown that depression, anxiety, and stress negatively affect life satisfaction irrespective of gender and geographical location(Cömert et al., 2016; Tonsing, 2014). Similarly, previous evidences show that depression, anxiety, and stress negatively affect well-being in different groups irrespective of race, place, and gender (Bhullar et al., 2014; Davis et al., 2016; Ryan et al., 2019).

Considering the effects of physiological distress on life satisfaction and wellbeing, reported during both normal and pandemic times, the present study investigated the following relationships:

a) The relationship of depression with life satisfaction and wellbeing during the two waves of the COVID-19 pandemic

b) The relationship of anxiety with life satisfaction and wellbeing during the two waves of the COVID-19 pandemic

c) The relationship of stress with life satisfaction and wellbeing during the two waves of the COVID-19 pandemic

d) The role of gender in the above-mentioned relationships during the two waves of the COVID-19 pandemic.

The proposed model is shown in Fig. 1.

\section{Methods}

\section{Participants}

A survey was conducted during the two waves-June 2020 (during COVID-19 first wave, T1) and May 2021 (during COVID-19 s wave, T2). Eight hundred eighty-four respondents 

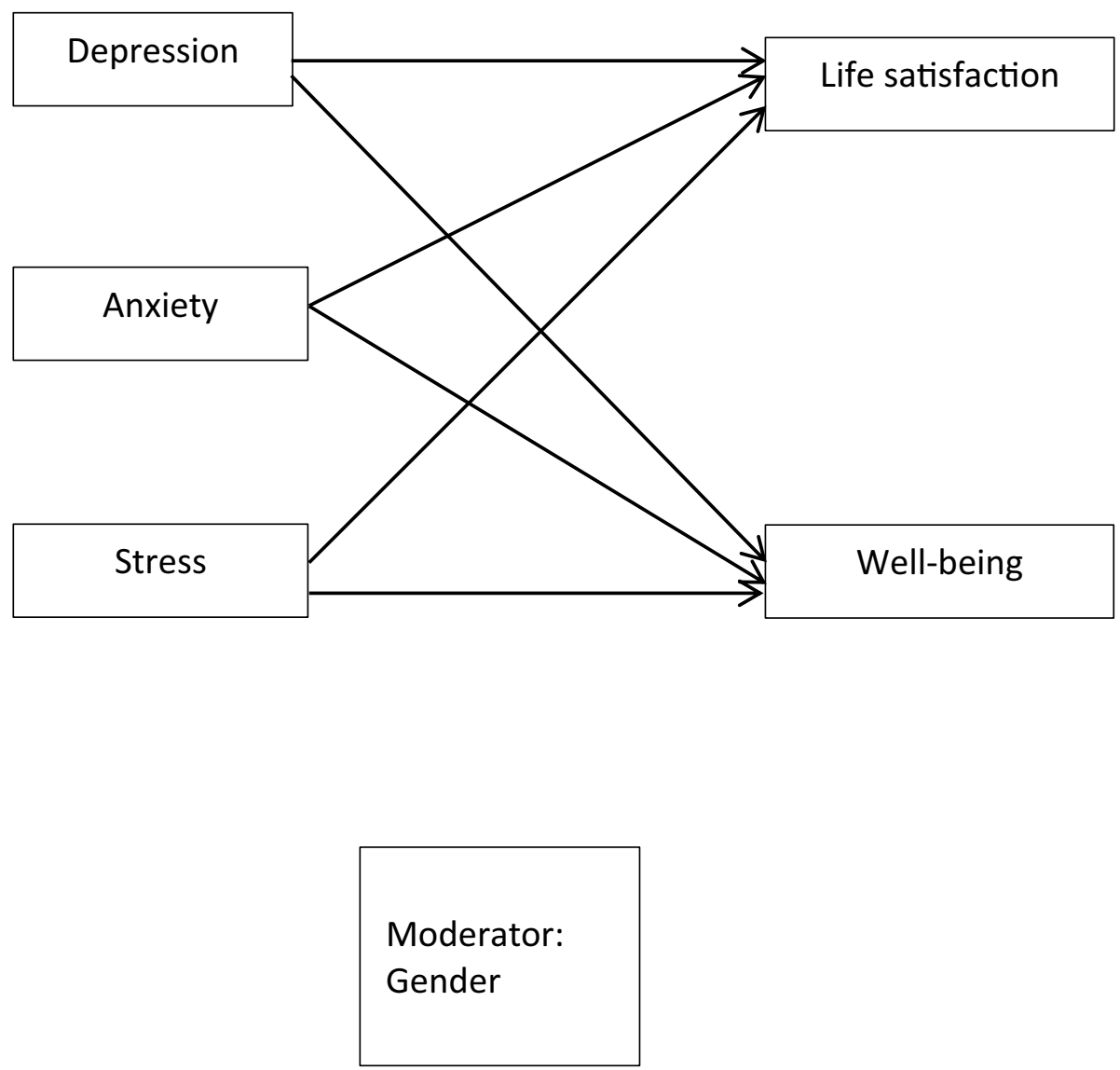

Fig. 1 Proposed model

took the survey during T1 (mean age 39.5, SD 10.5) and 925 during T2 (mean age 38.7, SD 9.5). In T1, 540 respondents were men and 344 were women. In T2, the sample comprised 467 men and 458 women. One hundred thirty-eight participants (96 men and 42 women) participated in both surveys. The survey was conducted through online Google forms during both waves and social media platforms were used to reach people. The snowball sampling strategy was used for collecting data.

\section{Measures}

The latent variables we considered for the study were depression, anxiety, stress, wellbeing, and life satisfaction. The natures of measures are described below:

\section{Depression Anxiety Stress Scale}

Depression, anxiety, and stress were assessed using the Depression Anxiety Stress Scale (DASS-21) (Lovibond \& Lovibond, 1996). DASS-21 comprises 21 items and three 
dimensions (seven items per dimension) (e.g., "I could not seem to experience any positive feeling at all" for depression; "I was worried about situations in which I might panic" for anxiety; and "I found it difficult to relax" for stress). The participants responded on a five-point Likert scale from 1 (did not apply to me at all) to 5 (most of the time). Higher scores on the three dimension reflected higher depression, anxiety, and stress. Given the importance of mental health concerns during the pandemic period, this 21 -item scale has been widely validated in various countries including China (Cuiyan et al., 2020), the USA (Wang et al. 2021e), Spain (Wang et al. 2021c), Poland (Wang et al. 2020a, 2020b), Iran (Wang et al. 2021b), Vietnam (Le et al., 2020), Philippines (Tee et al., 2020), and India (Lathabhavan et al., 2021).

\section{Wellbeing}

Wellbeing was measured using the WHO-Five Well-being Index (WHO-5). Sample item is "I have felt calm and relaxed". A five-point Likert-type scale was used with anchors 1 (strongly disagree) to 5 (strongly agree). The Cronbach's alpha was 0.84 for this study.

\section{Life Satisfaction}

Life satisfaction was measured using Satisfaction with Life Scale. Participants completed the SWLS (Diener et al., 1985), which asked direct questions about life satisfaction (e.g., "In most ways my life is close to my ideal" and "I am satisfied with my life"), which were answered on a 5-point Likert scale.

The observed variable considered for the study is gender. We used dummy variables to represent the responses male $=1$, female $=2$ for SPSS entry. For AMOS, we created different for gender and fetched data from the SPSS data file. Though we collected data for other observed variables such as age and marital status, we did not consider for the present study since we focused for more specific outcome rather a generalized one.

\section{Data Analysis}

The Structural Equation Modeling (SEM) method that was implemented using AMOS 24.0 (Arbuckle, 2016) was used to test the research model. Confirmatory Factor Analysis (CFA) was performed with maximum likelihood estimation to examine the goodness of fit of the model. The models' goodness of fit was evaluated using the criteria: relative $\chi^{2}:\left(\chi^{2} / \mathrm{df}\right)<3$, root mean square error of approximation (RMSEA): $\leqslant 0.08$, standardized root mean square residual (SRMR): $\leqslant 0.06$, Goodness of fit index (GFI) $\geqslant 0.90$, comparative fit index (CFI) $\geqslant 0.90$, and Tucker-Lewis index (TLI) $\geqslant 0.90$ (Byrne, 2013; Hu \& Bentler, 1998). Cronbach's $\alpha$, average variance extracted (AVE), composite reliability (CR), and average loadings (AL) were also used to check the reliability and validity of the instruments.

\section{Results}

\section{Descriptive Statistics}

The descriptive statistics of the study in two waves T1 and T2 are shown in Table 1. All significant relationships were in the expected direction. 


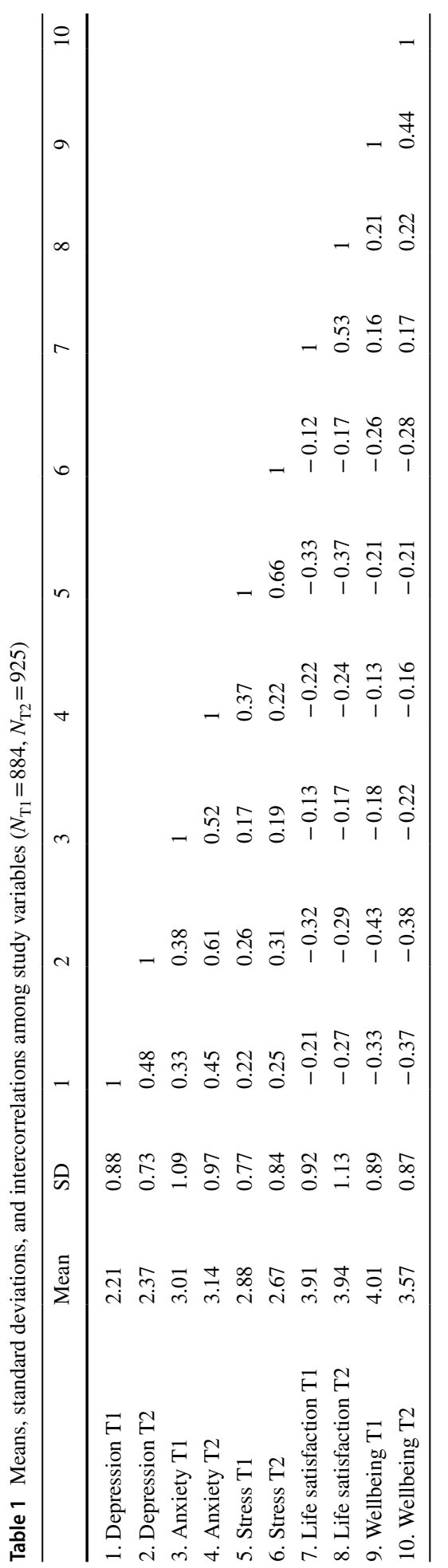


Table 2 Validity and reliability results

\begin{tabular}{|c|c|c|c|c|c|c|c|c|}
\hline & \multicolumn{2}{|l|}{$\mathrm{AL}$} & \multicolumn{2}{|l|}{ CR } & \multicolumn{2}{|l|}{ AVE } & \multicolumn{2}{|c|}{ Cronbach's $\alpha$} \\
\hline & $\mathrm{T} 1$ & $\mathrm{~T} 2$ & $\mathrm{~T} 1$ & $\mathrm{~T} 2$ & $\mathrm{~T} 1$ & $\mathrm{~T} 2$ & $\mathrm{~T} 1$ & $\mathrm{~T} 2$ \\
\hline Depression & 0.78 & 0.82 & 0.857 & 0.882 & 0.765 & 0.683 & 0.887 & 0.892 \\
\hline Anxiety & 0.81 & 0.79 & 0.793 & 0.781 & 0.677 & 0.712 & 0.843 & 0.854 \\
\hline Stress & 0.82 & 0.83 & 0.824 & 0.822 & 0.813 & 0.834 & 0.871 & 0.873 \\
\hline Life satisfaction & 0.77 & 0.78 & 0.836 & 0.843 & 0.775 & 0.785 & 0.833 & 0.843 \\
\hline Wellbeing & 0.83 & 0.84 & 0.897 & 0.883 & 0.734 & 0.745 & 0.891 & 0.901 \\
\hline
\end{tabular}

Table 3 Structural equation modeling results

\begin{tabular}{lll}
\hline Relationships & \multicolumn{2}{l}{ Standardized path coefficient } \\
\cline { 2 - 3 } & $\mathrm{T} 1(N=884)$ & $\mathrm{T} 2(N=925)$ \\
\hline Depression --> Life satisfaction & $-0.23^{* *}$ & $-0.32^{*}$ \\
Depression--> Wellbeing & $-0.33^{* *}$ & $-0.45^{* * *}$ \\
Anxiety--> Life satisfaction & $-0.18^{*}$ & $-0.22^{* *}$ \\
Anxiety --> Wellbeing & $-0.21^{* *}$ & $-0.25^{* *}$ \\
Stress --> Life satisfaction & $-0.42^{*}$ & $-0.44^{* *}$ \\
Stress --> Wellbeing & $-0.28^{* * *}$ & $-0.33^{*}$ \\
\hline
\end{tabular}

${ }^{*} p<0.5, * * p<0.01, * * * p<0.001$

\section{Common method bias}

Common method bias (CMB) happens when variations in responses are caused by the instrument rather than the actual predispositions of the respondents that the instrument attempts to uncover. On account of a common instrument used for measuring all the variables with different kind of scales, the Common Method Bias (CMB) was assessed. Harman's single factor test was employed for this purpose. CMB was assessed by factor analysis using SPSS 22.0, in which, all the items were loaded with a threshold to attain one factor. The results showed that a single factor contributed $29.665 \%$ of total variance extracted for $\mathrm{T} 1$ and $27.24 \%$ of total variance extracted for $\mathrm{T} 2$, which is below $50 \%$. This confirmed that $\mathrm{CMB}$ was not a major concern for this study.

\section{Reliability and Validity}

Table 2 shows the details of reliability and validity.

The average variance extracted (AVE) values were above 0.50 indicating excellent content and convergent validity of all the measures. The item loadings varied from 0.64 to 0.93 , also supporting the validity as all the loadings were above the threshold of 0.60 . The composite reliability of all latent variables was above 0.75 and adequate. The Cronbach's alpha values of variables exceeded the threshold value of 0.70 (Nunnally, 1994). Table 3 shows the discriminant validity details. Discriminant validity was deemed established as the square roots of all AVE scores were higher than their corresponding 
inter-correlations. Based on the above findings, it can be inferred that the measurement model exhibited an adequate level of reliability and validity.

\section{Structural Equation Modeling Results}

The results of SEM analysis showed that the proposed model (Fig. 1) was a good fit to the data during both waves. During the first wave, the model fit was good with $\chi^{2} / \mathrm{df}$ $(\mathrm{T} 1)=1.57, p<0.01, \mathrm{CFI}_{\mathrm{T} 1}=0.94, \mathrm{TLI}_{\mathrm{T} 1}=0.92, \mathrm{RMSEA}_{\mathrm{T} 1}=0.05$, and $\mathrm{SRMR}_{\mathrm{T} 1}=0.05$. Model fit during the second wave study was also good with $\chi^{2} / \mathrm{df}(\mathrm{T} 2)=1.69, p<0.01$, $\mathrm{CFI}_{\mathrm{T} 2}=0.95, \mathrm{TLI}_{\mathrm{T} 2}=0.95, \mathrm{RMSEA}_{\mathrm{T} 2}=0.04$, and $\mathrm{SRMR}_{\mathrm{T} 2}=0.05$.

All relationships were found to be significant and acceptable in both $\mathrm{T} 1$ and $\mathrm{T} 2$. The results of structural equation modeling are shown in Table 3. During the first wave of COVID-19 in India, depression had shown significant negative relationships with the dependent variables. The relationships of depression was found to be significant with life satisfaction $\left(\beta_{\mathrm{T} 1}=-0.23, p<0.01\right)$ and wellbeing $\left(\beta_{\mathrm{T} 1}=-0.32, p<0.05\right)$. Anxiety also reported significant relationship with life satisfaction $\left(\beta_{\mathrm{T} 1}=-0.18, p<0.05\right)$ and wellbeing $\left(\beta_{\mathrm{T} 1}=-0.21, p<0.01\right)$ during the first wave. The relationships of stress with life satisfaction $\left(\beta_{\mathrm{T} 1}=-0.42, p<0.05\right)$ and wellbeing $\left(\beta_{\mathrm{T} 1}=-0.28, p<0.001\right)$ were also found significant during the first wave study.

During the second wave of COVID-19, significant relationships were seen, as before. The second wave study reported negative significant relationships of depression with life satisfaction $\left(\beta_{\mathrm{T} 2}=-0.32, p<0.05\right)$ and wellbeing $\left(\beta_{\mathrm{T} 2}=-0.45, p<0.001\right)$. During the second wave, anxiety was found negatively related to life satisfaction $\left(\beta_{\mathrm{T} 2}=-0.22, p<0.01\right)$ and wellbeing $\left(\beta_{\mathrm{T} 2}=-0.25, p<0.01\right)$. Stress also related negatively during the second wave with life satisfaction $\left(\beta_{\mathrm{T} 2}=-0.44, p<0.01\right)$ and wellbeing $\left(\beta_{\mathrm{T} 2}=-0.33, p<0.05\right)$.

\section{Moderation Analysis-Gender}

In order to analyze the moderating role of gender on life satisfaction and wellbeing during the two waves, multi-group analysis through SEM was used. Table 4 shows the moderation analysis of the two-wave study. In both waves, all relationships were found to be stronger in women than in men.

Table 4 Moderation analysis

\begin{tabular}{|c|c|c|c|c|c|c|}
\hline \multirow[t]{2}{*}{ Relationships } & \multicolumn{3}{|c|}{ Path coefficient (T1) } & \multicolumn{3}{|c|}{ Path coefficient (T2) } \\
\hline & Male & Female & Difference & Male & Female & Difference \\
\hline Depression--> Life satisfaction & $-0.19^{*}$ & $-0.24 * *$ & 0.05 & $-0.28 * *$ & $-0.34 * *$ & 0.06 \\
\hline Depression --> Wellbeing & $-0.23 * *$ & $-0.45^{* *}$ & $0.22 * *$ & $-0.43 *$ & $-0.49 *$ & 0.06 \\
\hline Anxiety --> Life satisfaction & $-0.16^{* *}$ & $-0.19 *$ & 0.03 & $-0.21 * *$ & $-0.28 * *$ & 0.07 \\
\hline Anxiety --> Wellbeing & $-0.22 *$ & $-0.29 *$ & 0.05 & $-0.26^{*}$ & $-0.45^{*}$ & $0.19 *$ \\
\hline Stress--> Life satisfaction & $-0.33 * *$ & $-0.52 *$ & $0.21 * *$ & $-0.43 * *$ & $-0.53 * *$ & 0.10 \\
\hline Stress --> Wellbeing & $-0.26^{*}$ & $-0.34 * *$ & 0.08 & $-0.29 *$ & $-0.37 *$ & 0.08 \\
\hline
\end{tabular}

${ }^{*} p<0.5, * * p<0.01, * * * p<0.001$ 


\section{Discussion}

The main aim of the present study was to examine and compare the relationships of psychological distress on life satisfaction and wellbeing during the two COVID-19 waves in India. A study was conducted during June 2020 and May 2021, corresponding to the first and second waves. Online surveys were conducted among 884 (T1) and 925 (T2) samples during the two waves.

The present study reported negative relationships of depression with life satisfaction and wellbeing. The study reinforced the relationship in light of previous studies in this area (Padmanabhanunni \& Pretorius, 2021; Smith et al., 2020). During the second wave, the effects of depression on life satisfaction and wellbeing were stronger. The effects of depression were higher among women than men. The study revealed the strong negative relationships of anxiety with life satisfaction and wellbeing during both waves. Comparing the time span, in the second wave, the relationships were stronger. In both waves, the effects of anxiety with life satisfaction and wellbeing were slightly higher among women than men. Thus, the study supported the previous finding in this area (Gallagher et al., 2021; Smith et al., 2020). The relationships of stress with life satisfaction and wellbeing were found to be strongly negative during both waves. The severity of stress during the second wave and among women was visible in the study. This is in line with previous observations that stress severely affected life satisfaction and wellbeing of people around the globe during the pandemic (Dymecka et al., 2021; Lathabhavan \& Vispute, 2021).

The study showed that psychological distress during the COVID-19 s wave was more severe than during the first wave in India. This could be attributed to unexpected spikes in infection and death toll during this time. Oxygen shortages and unavailability of patient beds during the second wave could also have caused increased psychological distress, that negatively affected life satisfaction and wellbeing. The study also revealed that women face more psychological distress and this affects their wellbeing during times of crisis (Choi et al., 2021). Thus the study supported the previous findings of longitudinal studies conducted in this domain during the pandemic (Wang et al. 2020b).

Since the second wave of COVID-19 affected India severely, the mental health issues were also severe and affected the wellbeing of people. During the pandemic, online psychological interventions are the best option to help the general public in this matter. The most evidence-based treatment has been shown to be cognitive behavior therapy (CBT), especially Internet CBT for the prevention and control of psychological issues during the pandemic (Ho et al. 2020a; Ho et al. 2020b; Soh et al., 2020; Zhang \& Ho, 2017). A structured health care system with collaboration between health care workers, mental health specialists, policy makers of all levels has been shown to be beneficial to society (Lathabhavan, 2021d). Along with strong health care measures, people must be trained in coping mechanisms and stress management strategies (Lathabhavan et al., 2017). Family members and friends can help each other by understanding the mental health problems of their loved ones and can seek psychological expert advices for the same.

The study has a few limitations. The COVID-19 pandemic has been shown to cause hemodynamic changes in the brain (Olszewska-Guizzo et al., 2021). This study mainly used self-reported questionnaires to measure psychiatric symptoms and did not make a clinical diagnosis. The gold standard for establishing psychiatric diagnosis involves a structured clinical interview and functional neuroimaging (Ho et al. 2020a; Ho et al. 2020b; Husain et al. 2020a; Husain et al. 2020b). Future researches in this area can focus on the mentioned aspects and different psychological variables, so that an overall approach can be 
considered. Furthermore, future studies can consider other observed and unobserved factors that may affect life satisfaction and well-being, for a clearer picture of the issue. Geography-specific studies can also help understand differences and similarities across regions.

\section{Conclusion}

Both waves of the COVID-19 pandemic have been associated with psychological distress in India. This study showed that depression, anxiety, and stress negatively were related to wellbeing and satisfaction during both waves of the pandemic. These relationships were found to be stronger during the second wave than the first. The mental health of women was found to be affected more than that of men during both waves. Psychological help by self, family, and medical practitioners can help overcome these problems and help in the development of better coping mechanisms during times of crisis.

\section{References}

Arbuckle, J. L. (2016). IBM® SPSS® User's Guide Amos ${ }^{\mathrm{TM}} 24$. IBM, Chicago, IL., 1-720. ftp://public.dhe. ibm.com

Bhullar, N., Hine, D. W., \& Phillips, W. J. (2014). Profiles of psychological well-being in a sample of Australian university students. International Journal of Psychology, 49(4), 288-294. https://doi.org/10. 1002/ijop.12022

Byrne, B. M. (2013). Structural Equation Modeling with AMOS: Basic Concepts, Applications, and Programming. Routledge.

Choi, E. P. H., Hui, B. P. H., \& Wan, E. Y. F. (2020). Depression and anxiety in Hong Kong during COVID19. International Journal of Environmental Research and Public Health, 17(10). https://doi.org/10. 3390/ijerph17103740

Choi, I. I., Kim, J. H., Kim, N., Id, E. C., Choi, J., Suk, W., \& Na, J. (2021). How COVID-19 affected mental well-being : An 11- week trajectories of daily well-being of Koreans amidst COVID-19 by age , gender and region. PLoS One, 16(4). https://doi.org/10.1371/journal.pone.0250252

Cömert, I. T., Özyeşil, Z. A., \& Burcu Özgülük, S. (2016). Satisfaction with life, meaning in life, sad childhood experiences, and psychological symptoms among Turkish students. Psychological Reports, 118(1), 236-250. https://doi.org/10.1177/0033294115626634

Cuiyan, W., Riyu, P., Xiaoyang, W., Yilin, T., Linkang, X., Cyrus, S. H., \& C.H., R. (2020). Immediate psychological responses and associated factors during the initial stage of the 2019 coronavirus disease (COVID-19) epidemic among the general population in China. International Journal of Environmental Research and Public Health, 17(5), 1-25.

Davis, T. J., Morris, M., \& Drake, M. M. (2016). The moderation effect of mindfulness on the relationship between adult attachment and wellbeing. Personality and Individual Differences, 96, 115-121. https:// doi.org/10.1016/j.paid.2016.02.080

Diener, E., \& EMMONS, R. A., LAR.SEM, R. J., \& GRIFFIN, S. (1985). The Satisfaction With Life Scale. Journal of Personality Assessment, 49(1), 71-75. https://doi.org/10.4324/9781003035312-41

Dymecka, J., Gerymski, R., Machnik, A., \& Machnik-czerwik, A. (2021). How does stress affect life satisfaction during the COVID-19 pandemic ? Moderated mediation analysis of sense coherence and fear of coronavirus. Psychology Health and Medicine. https://doi.org/10.1080/13548506.2021.1906436

El-Bardan, M. F., \& Lathabhavan, R. (2021). Fear of COVID-19 scale: psychometric properties, reliability and validity in Egypt. Diabetes \& Metabolic Syndrome: Clinical Research \& Reviews.

Gallagher, M. W., Smith, L. J., Richardson, A. L., D’Souza, J. M., \& Long, L. J. (2021). Examining the longitudinal effects and potential mechanisms of hope on COVID-19 stress, anxiety, and well-being. Cognitive Behaviour Therapy, 50(3), 234-245. https://doi.org/10.1080/16506073.2021.1877341

Hao, F., Tan, W., Jiang, L., Zhang, L., Zhao, X., Zou, Y., Hu, Y., Luo, X., Jiang, X., McIntyre, R. S., Tran, B., Sun, J., Zhang, Z., Ho, R., Ho, C., \& Tam, W. (2020). Do psychiatric patients experience more psychiatric symptoms during COVID-19 pandemic and lockdown? A case-control study with service and research implications for immunopsychiatry. Brain, Behavior, and Immunity, 87(April), 100-106. https://doi.org/10.1016/j.bbi.2020.04.069 
Ho, C. S., Chee, C. Y., \& Ho, R. C. (2020a). Mental health strategies to combat the psychological impact of COVID-19 beyond paranoia and panic. Annals of the Academy of Medicine, Singapore, 49(1), $1-3$.

Ho, C. S. H., Lim, L. J. H., Lim, A. Q., Chan, N. H. C., Tan, R. S., Lee, S. H., \& Ho, R. C. M. (2020). Diagnostic and predictive applications of functional near-infrared spectroscopy for major depressive disorder: A systematic review. Frontiers in Psychiatry, 11(May). https://doi.org/10.3389/fpsyt.2020.00378

Hu, L. T., \& Bentler, P. M. (1998). Fit indices in covariance structure modeling: Sensitivity to underparameterized model misspecification. Psychological Methods, 3(4), 424-453. https://doi.org/10. 1037/1082-989X.3.4.424

Husain, S. F., Tang, T. B., Yu, R., Tam, W. W., Tran, B., Quek, T. T., Hwang, S. H., Chang, C. W., Ho, C. S., \& Ho, R. C. (2020a). Cortical haemodynamic response measured by functional near infrared spectroscopy during a verbal fluency task in patients with major depression and borderline personality disorder. eBioMedicine, 51, 102586. https://doi.org/10.1016/j.ebiom.2019.11.047

Husain, S. F., Yu, R., Tang, T. B., Tam, W. W., Tran, B., Quek, T. T., Hwang, S. H., Chang, C. W., Ho, C. S., \& Ho, R. C. (2020b). Validating a functional near-infrared spectroscopy diagnostic paradigm for Major Depressive Disorder. Scientific Reports, 10(1), 1-9. https://doi.org/10.1038/s41598-020-66784-2

Kontoangelos, K., Economou, M., \& Papageorgiou, C. (2020). Mental Health Effects of COVID-19 Pandemia : A Review of Clinical and Psychological Traits. Psychiatry Investigation, 17(6), 491-505.

Lathabhavan, R. (2021a). A psychometric analysis of fear of COVID-19 scale in India. International Journal of Mental Health and Addiction, 0123456789. https://doi.org/10.1007/s11469-021-00657-1

Lathabhavan, R. (2021b). COVID-19 effects on psychological outcomes : How do gender responses differ ? Psychological Reports. https://doi.org/10.1177/00332941211040428

Lathabhavan, R. (2021c). First and second waves of COVID-19: A comparative study on the impact of pandemic fear on the mental health of university students in India. Journal of Loss and Trauma, O(0), 1-2. https://doi.org/10.1080/15325024.2021.1950432

Lathabhavan, R. (2021d). People and social media platforms for positive mental health- A paradigm shift: A case on COVID-19 impact form India. Asian Journal of Psychiatry, 56(October 2020), 102460. https://doi.org/10.1016/j.ajp.2020.102460

Lathabhavan, R., Balasubramanian, S. A., \& Natarajan, T. (2017). A psychometric analysis of the Utrecht Work Engagement Scale in Indian banking sector. Industrial and Commercial Training, 49(6). https://doi.org/10.1108/ICT-04-2017-0031

Lathabhavan, R., \& Barami.A, N., Kurikkal, M. P. M. M., \& Manoj, N. (2021). Mental health concerns of small business entrepreneurs in India due to COVID-19 financial distress. Asian Journal of Psychiatry. https://doi.org/10.1080/13518040701205365

Lathabhavan, R., Kurikkal, M. P. M. M., Manoj, N., \& Barami. A., N. (2021). Mental Health concerns due to pandemic fear and financial distress on employees in India during the pandemic: a cross-sectional multi-group study. Journal of Loss and Trauma, 1-2. https://doi.org/10.1080/15325024.2021.1989190

Lathabhavan, R., \& Padhy, P. C. (2022). Role of fear of COVID-19 in the relationship of problematic internet use and stress : A retrospective cohort study among Gen X, Y and Z. Asian Journal of Psychiatry, 67, 102937. https://doi.org/10.1016/j.ajp.2021.102937

Lathabhavan, R., \& Vispute, S. (2021). Examining the mediating effects of stress on fear of COVID-19 and well-being using structural equation modeling. International Journal of Mental Health and Addiction.

Le, H. T., Lai, A. J. X., Sun, J., Hoang, M. T., Vu, L. G., Pham, H. Q., Nguyen, T. H., Tran, B. X., Latkin, C. A., Le, X. T. T., Nguyen, T. T., Pham, Q. T., Ta, N. T. K., Nguyen, Q. T., Ho, R. C. M., \& Ho, C. S. H. (2020). Anxiety and depression among people under the nationwide partial lockdown in Vietnam. Frontiers in Public Health, 8(October), 1-8. https://doi.org/10.3389/fpubh.2020.589359

Lee, Y., Lui, L. M. W., Chen-Li, D., Liao, Y., Mansur, R. B., Brietzke, E., Rosenblat, J. D., Ho, R., Rodrigues, N. B., Lipsitz, O., Nasri, F., Cao, B., Subramaniapillai, M., Gill, H., Lu, C., \& McIntyre, R. S. (2021). Government response moderates the mental health impact of COVID-19: A systematic review and meta-analysis of depression outcomes across countries. Journal of Affective Disorders, 290(May), 364-377. https://doi.org/10.1016/j.jad.2021.04.050

Lovibond, S. H., \& Lovibond, P. F. (1996). Manual for the depression anxiety stress scales. In Psychology Foundation of Australia.

Moghanibashi-mansourieh, A. (2020). Assessing the anxiety level of Iranian general population during COVID-19 outbreak. Asian Journal of Psychiatry, January.

Nunnally, J. C. (1994). Psychometric theory. Tata McGraw-hill education.

Olszewska-Guizzo, A., Mukoyama, A., Naganawa, S., Dan, I., Husain, S. F., Ho, C. S., \& Ho, R. (2021). Hemodynamic response to three types of urban spaces before and after lockdown during the COVID-19 pandemic. International Journal of Environmental Research and Public Health, 18(11). https://doi.org/10.3390/ijerph18116118 
Padmanabhanunni, A., \& Pretorius, T. (2021). The loneliness-life satisfaction relationship: The parallel and serial mediating role of hopelessness, depression and ego-resilience among young adults in South Africa during covid-19. International Journal of Environmental Research and Public Health, 18(7). https://doi.org/10.3390/ijerph18073613

Reznik, A., Gritsenko, V., Konstantinov, V., Khamenka, N., \& Isralowitz, R. (2020). COVID-19 fear in Eastern Europe : Validation of the fear of COVID-19 scale. International Journal of Mental Health and Addiction, 1-6.

Ryan, J., Curtis, R., Olds, T., Edney, S., Vandelanotte, C., Plotnikoff, R., \& Maher, C. (2019). Psychometric properties of the PERMA Profiler for measuring wellbeing in Australian adults. PLoS ONE, 14(12), 1-12. https://doi.org/10.1371/journal.pone.0225932

Smith, L., Jacob, L., Yakkundi, A., McDermott, D., Armstrong, N. C., Barnett, Y., López-Sánchez, G. F., Martin, S., Butler, L., \& Tully, M. A. (2020). Correlates of symptoms of anxiety and depression and mental wellbeing associated with COVID-19: A cross-sectional study of UK-based respondents. Psychiatry Research, 291(May), 113138. https://doi.org/10.1016/j.psychres.2020.113138

Soh, H. L., Ho, R. C., Ho, C. S., \& Tam, W. W. (2020). Efficacy of digital cognitive behavioural therapy for insomnia: A meta-analysis of randomised controlled trials. Sleep Medicine, 75, 315-325. https://doi. org/10.1016/j.sleep.2020.08.020

Tandon, R. (2020). COVID-19 and mental health: Preserving humanity, maintaining sanity, and promoting health. Asian Journal of Psychiatry, 51.

Tee, M. L., Tee, C. A., Anlacan, J. P., Aligam, K. J. G., Wincy, P., Reyes, C., Kuruchittham, V., \& Ho, R. C. (2020). Psychological impact of COVID-19 pandemic in the Philippines. Journal of Affective Disorders, 277, 379-391.

Tonsing, K. N. (2014). Psychometric properties and validation of Nepali version of the Depression Anxiety Stress Scales (DASS-21). Asian Journal of Psychiatry, 8(1), 63-66. https://doi.org/10.1016/j.ajp.2013. 11.001

Ustun, G. (2021). Determining depression and related factors in a society affected by COVID-19 pandemic. International Journal of Social Psychiatry, 67(1), 54-63. https://doi.org/10.1177/0020764020938807

Wang, C., Chudzicka-Czupała, A., Grabowski, D., Pan, R., Adamus, K., Wan, X., Hetnał, M., Tan, Y., Olszewska-Guizzo, A., Xu, L., McIntyre, R. S., Quek, J., Ho, R., \& Ho, C. (2020a). The association between physical and mental health and face mask use during the COVID-19 pandemic: A comparison of two countries with different views and practices. Frontiers in Psychiatry, 11, 1-13. https://doi.org/ $10.3389 /$ fpsyt.2020.569981

Wang, C., Chudzicka-Czupała, A., Tee, M. L., Núñez, M. I. L., Tripp, C., Fardin, M. A., Habib, H. A., Tran, B. X., Adamus, K., Anlacan, J., García, M. E. A., Grabowski, D., Hussain, S., Hoang, M. T., Hetnał, M., Le, X. T., Ma, W., Pham, H. Q., Reyes, P. W. C., ... Sears, S. F. (2021a). A chain mediation model on COVID-19 symptoms and mental health outcomes in Americans, Asians and Europeans. Scientific Reports, 11(1), 1-12. https://doi.org/10.1038/s41598-021-85943-7

Wang, C., Fardin, M. A., Shirazi, M., Pan, R., Wan, X., Tan, Y., Xu, L., McIntyre, R. S., Tran, B., Quek, T. T. C., Husain, S. F., Wang, J., Ho, C., \& Ho, R. (2021b). Mental health of the general population during the 2019 coronavirus disease (COVID-19) pandemic: A tale of two developing countries. Psychiatry International, 2(1), 71-84. https://doi.org/10.3390/psychiatryint2010006

Wang, C., López-Núñez, M. I., Pan, R., Wan, X., Tan, Y., Xu, L., Choo, F., Ho, R., Ho, C., \& Aparicio García, M. E. (2021c). The impact of the COVID-19 pandemic on physical and mental health in China and Spain: Cross-sectional study. JMIR Formative Research, 5(5), 1-10. https://doi.org/10.2196/27818

Wang, C., Pan, R., Wan, X., Tan, Y., Xu, L., McIntyre, R. S., Choo, F. N., Tran, B., Ho, R., Sharma, V. K., \& Ho, C. (2020b). A longitudinal study on the mental health of general population during the COVID19 epidemic in China. Brain, Behavior, and Immunity, 87, 40-48. https://doi.org/10.1016/j.bbi.2020. 04.028

Wang, C., Tee, M., Roy, A. E., Fardin, M. A., Srichokchatchawan, W., Habib, H. A., Tran, B. X., Hussain, S., Hoang, M. T., Le, X. T., Ma, W., Pham, H. Q., Shirazi, M., Taneepanichskul, N., Tan, Y., Tee, C., Xu, L., Xu, Z., Vu, G. T., ... Kuruchittham, V. (2021e). The impact of COVID-19 pandemic on physical and mental health of Asians: A study of seven middle-income countries in Asia. PLoS ONE, 16(2 Febuary), 1-20. https://doi.org/10.1371/journal.pone.0246824

Wang, C., Tripp, C., Sears, S. F., Xu, L., Tan, Y., Zhou, D., Ma, W., Xu, Z., Chan, N. A., Ho, C., \& Ho, R. (2021e). The impact of the COVID-19 pandemic on physical and mental health in the two largest economies in the world: A comparison between the United States and China. Journal of Behavioral Medicine. https://doi.org/10.1007/s10865-021-00237-7

WHO. (2021). https://www.who.int/countries/ind/.

Xiong, J., Lipsitz, O., Nasri, F., Lui, L. M. W., Gill, H., Phan, L., Chen-Li, D., Iacobucci, M., Ho, R., Majeed, A., \& McIntyre, R. S. (2020). Impact of COVID-19 pandemic on mental health in the general 
population: A systematic review. Journal of Affective Disorders, 277, 55-64. https://doi.org/10.1016/j. jad.2020.08.001

Yom-Tov, E., Lekkas, D., \& Jacobson, N. C. (2021). Association of COVID19-induced anosmia and ageusia with depression and suicidal ideation. Journal of Affective Disorders Reports, 5(May), 100156. https:// doi.org/10.1016/j.jadr.2021.100156

Zhang, M. W. B., \& Ho, R. C. M. (2017). Moodle: The cost effective solution for internet cognitive behavioral therapy (I-CBT) interventions. Technology and Health Care, 25(1), 163-165. https://doi.org/10. 3233/THC-161261

Zhang, S. X., Wang, Y., Rauch, A., \& Wei, F. (2020). Unprecedented disruption of lives and work : Health , distress and life satisfaction of working adults in China one month into the COVID-19 outbreak. Psychiatry Research, January.

Publisher's Note Springer Nature remains neutral with regard to jurisdictional claims in published maps and institutional affiliations. 